\title{
Sulphasalazine and male infertility: reversibility and possible mechanism
}

\author{
S TOOVEY, ELIZABETH HUDSON, W F HENDRY, AND A J LEVI \\ From the Departments of Gastroenterology and Cytology, Northwick Park Hospital, and Clinical Research \\ Centre, Harrow, Middlesex, and Fertility Clinic, Chelsea Hospital for Women, London
}

SUMMARY Earlier observations on infertility related to sulphasalazine treatment were extended and semen samples obtained from 28 patients with inflammatory bowel disease on treatment with sulphasalazine at $2-4 \mathrm{~g}$ per day. Semen was examined for changes in density, motility, and morphology before, during, and after withdrawal of sulphasalazine. Gross semen abnormalities were seen in 18 patients on this drug for more than two months. Semen quality improved after sulphasalazine had been withdrawn for more than two months and 10 pregnancies are reported after sulphasazaine withdrawal. Preliminary endorrine and acetylator phenotype studies do not elucidate the mechanism of this important new side-effect of this drug. The time course of the drug's effect on semen quality is consistent with the hypothesis that sulphasalazine or a metabolite, possibly sulphapyridine, is directly toxic to developing spermatozoa. These studies confirmed the preliminary report and suggest that prolonged treatment with sulphasalazine may universally depress semen quality and cause reversible infertility.

Levi et al. ${ }^{1}$ gave details of four patients with sulphasalazine-associated infertility. Other reports have appeared in the literature. ${ }^{2-5}$ The aim of this study was to accumulate additional data on the nature and reversibility of semen abnormalities associated with sulphasalazine and to elucidate the mechanism involved.

\section{Methods}

C L I N I C A L S T U D Y

Twenty-eight male patients (age range 22-49 years) with histological and/or radiological documentation of inflammatory bowel disease, either ulcerative colitis or regional enteritis, were able to provide semen samples for the study. Consent was obtained from all patients. Semen was collected in a standardised way by masturbation into a sterile plastic container after at least 48 hours abstinence from seminal emission. Samples were kept at room temperature and analysed after liquefaction for (1) sperm density (normal range greater than or equal to $40 \times 10^{6}$ sperm $/ \mathrm{ml}$ ); (2) sperm motility (normal range greater than or equal to $60 \%$ progressively motile); (3) sperm morphology (normal range less than or equal to $30 \%$ abnormal forms). All samples were analysed R eceived for publication 5 February 1981 within two hours of production. Samples were then classified as belonging to one of five groups that depended on the nature of the treatment with sulphasalazine that the donor was being given, as indicated below.

Group 1 Four patients who had never taken sulphasalazine.

Group 2 Seven patients on a dose of 2-4 g sulphasalazine a day for less than two months.

Group 3 Eighteen patients on a dose of 2-4 g sulphasalazine a day for at least two months.

Group 4 Eight patients who had ceased taking sulphasalazine $2-4 \mathrm{~g}$ a day within the preceding two months, but who, before that, had completed a course of at least two months' duration.

Group 5 Fourteen patients who had completed a full two months' withdrawal from sulphasalazine therapy after taking it for at least two months.

Comparisons by means of a Mann-Whitney test were then made between the various groups. Subjects in group 3 were subdivided into those who had and had not complained of infertility. Nine patients in group 3 were separately analysed by Wilcoxon's matched pairs test in which the 
three aspects of semen quality were compared with results after two months of withdrawal. Eight out of the nine were similarly analysable after less than two months of drug withdrawal. Results are shown with mean \pm 1 SEM.

A C E T Y L A T OR P H E N O T Y E

The acetylator phenotypes of 14 patients on sulphasalazine therapy were determined by Schroder's method ${ }^{6}$ with analyses performed in triplicate. Fast and slow acetylator phenotype groups were then compared with each other with respect to each of the three semen qualities studied. A similar comparison was made after the exclusion of three patients who had belonged to group 2, the remaining 11 all belonging to group 3 .

\section{H O R M O N E S T U D I E S}

A modified gonadotrophin-releasing hormone (gonadorelin, GnRH) test was performed on 13 patients. Eleven of these had been on sulphasalazine for periods up to two years. Four patients were not taking sulphasalazine at the time of the study. Not all of these patients participated in the other aspects of this study. The test consisted of forearm vein cannulation and the drawing of venous blood samples for leuteinising hormone, follicle stimulating hormone, testosterone, 5alpha-dihydrotestosterone, and prolactin at the time intervals shown in the Tables. One hundred micrograms of gonadorelin (HRF, Ayerst HRF) was injected intravenously immediately after withdrawing the zero time samples. All samples were collected in plain glass tubes with the exception of those for testosterone and 5-alphadihydrotestosterone estimation which were collected into heparinised tubes. Samples were centrifuged and serum or plasma separated as appropriate and stored at $-70^{\circ} \mathrm{C}$ before analysis. All analyses were carried out by the endocrine laboratory of the Chelsea Hospital for Women. For technical reasons the sets of measurements were not complete in all patients.

Prolactin, leuteinising hormone, and follicle stimulating hormone were assayed by double antibody radioimmunoassay methods. Testosterone assay was by the method of Collins and Mansfield et al. ${ }^{7}$ and 5-alpha-dihydrotestosterone assay was by the method of Mansfield et al. ${ }^{8}$

\section{Results}

Four patients with newly diagnosed untreated inflammatory bowel disease (group 1) had normal sperm density $\left(54.0 \pm 3.9 \times 10^{6}\right.$ sperm $\left./ \mathrm{ml}\right)$ (Fig. 1), and morphology (Fig. 3) with motility approxi-

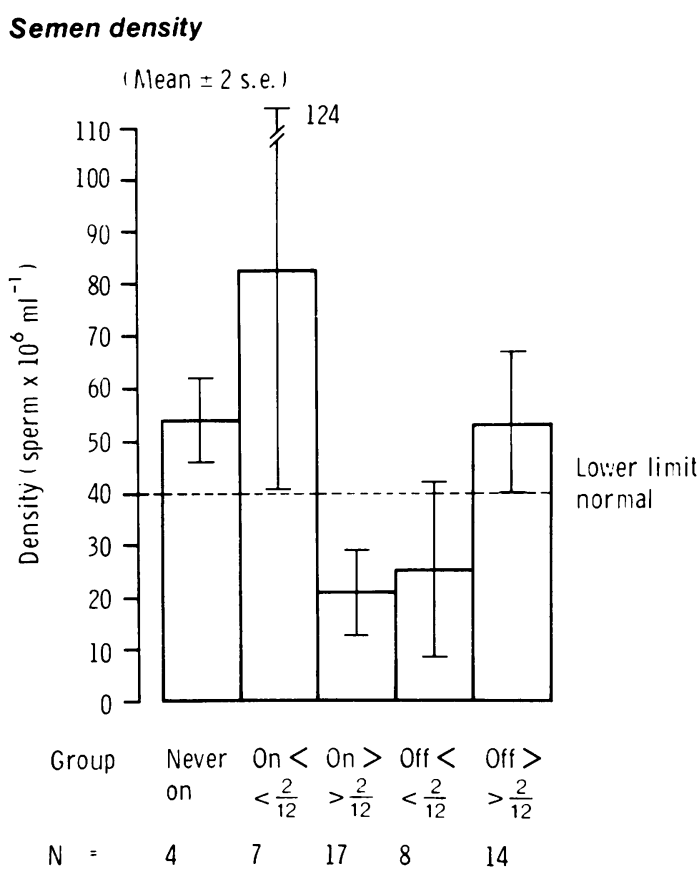

Fig. 1 Semen density in groups of patients before, during, and after treatment with sulphasalazine.

Lower limit of normal $40 \times 10^{6} \mathrm{ml}$.

Means $\pm 2 S E$ shown.

mating to normal $(55 \pm 9 \cdot 0 \%$ progressively motile forms) (Fig. 2). Patients treated for less than two months had markedly reduced motility $(30 \pm 1.5 \%$ progressively motile forms). This difference was significant at the $1 \%$ level in a Mann-Whitney test. Mean density was not significantly reduced $\left(82.5 \pm 21.9 \times 10^{6} \mathrm{sperm} / \mathrm{ml}\right)$, although two out of the seven patients in this group (group 2) had subriormal counts. Morphology was not significantly disturbed after less than two months of sulphasalazine therapy.

Patients treated for more than two months had significantly reduced density $\left(20.9 \pm 4.2 \times 10^{6}\right.$ sperm $/ \mathrm{ml})$ and motility ( $29 \pm 4 \cdot 2 \%$ progressively motile forms). Morphology was also significantly disturbed after two months of sulphasalazine therapy ( $39 \pm 4.5 \%$ abnormal forms). In a MannWhitney test these differences were significant at less than $1 \%$, at $2.5 \%$, and less than $5 \%$ for density, motility, and morphology respectively. Density and motility tended to improve within two months after sulphasalazine was withdrawn, although this did not reach significance. After two or more months of withdrawal the majority of patients, 11 out of 14 , had normal density $\left(53.5 \pm 6.9 \times 10^{6} \mathrm{srerm} / \mathrm{ml}\right)$, this value being sig- 


\section{Semen motility}

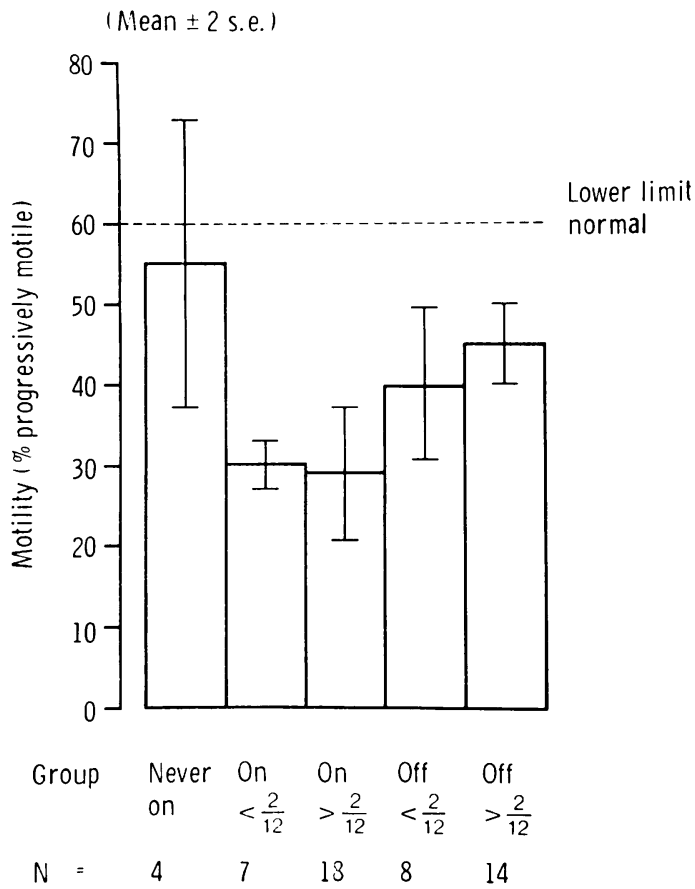

Fig. 2 Sperm motility in groups of patients before, during, and after treatment with sulphasalazine. Lower limit of normal $60 \%$. Means $\pm 2 S E$ shown.

nificantly better $(\mathrm{P}=<0.001$, Mann-Whitney $)$ than those on prolonged (longer than two months) sulphasalazine therapy. Motility rose concomitantly and was significantly improved $(\mathrm{P}=<0.01$, Mann-Whitney), but the mean failed to reach normal levels $(45 \pm 2.5 \%$ progressively motile forms).

Nine patients in group 3 were able to act as their own controls. After two months of sulphasalazine withdrawal density and motility improved significantly $(P=0.01$ and $P=0.025$ respectively, Mann-Whitney). Improvement was not evident in morphology. In eight of these nine in whom results were available at less than two months after withdrawal, no significant improvements were evident in any semen quality measured (Fig. 4).

Results obtained from patients in group 3 were subdivided into eight who had spontaneously complained of infertility and 10 who had not. Seven out of the eight complaining of infertility had previously fathered children, before sulphasalazine therapy. No significant differences were found between the two subgroups in a MannWhitney test (Table 1).

\section{Semen morphology}

(Mean \pm 2 s.e.)

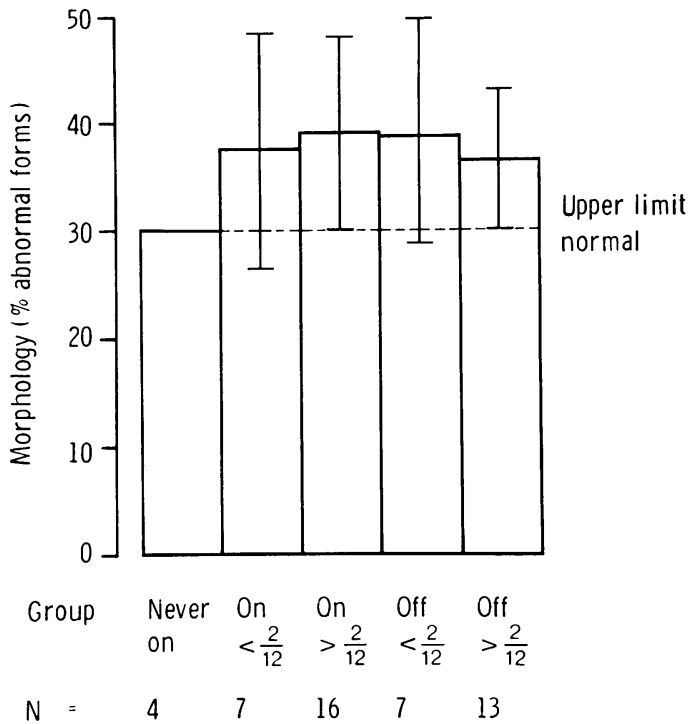

Fig. 3 Sperm morphology in groups of patients before, during, and after treatment with sulphasalazine. Lower limit of normal $30 \%$. Means $\pm 2 S E$ shown.

Ten pregnancies were fathered by eight patients after withdrawal of sulphasalazine (Table 2). The period of ingestion before withdrawal had a mean of three years with one patient having been on treatment for 10 years. The periods for patient 4 are not recorded accumulatively. The mean interval between withdrawal of sulphasalazine and subsequent successful impregnation was 2.5 months. Of these 10 pregnancies one resulted in a spontaneous abortion, five in full-term normal delivery, and four are still in utero at the time of writing.

No significant differences were evident in a Mann-Whitney test between the fast and slow acetylator phenotype with regard to the three semen qualities studied (Table 3). This was true whether or not the three patients who had been on sulphasalazine for less than two months were excluded. There were eight fast and six slow acetylators.

The results in the hormone studies are shown in Table 4. Comparisons by means of MannWhitney tests between the group of patients ingesting sulphasalazine at the time of testing and a group not ingesting sulphasalazine failed to reveal any significant differences. Table 4 shows the values of leuteinising hormone, follicle stimulating hormone, testosterone, 5-alpha-dihydrotes- 

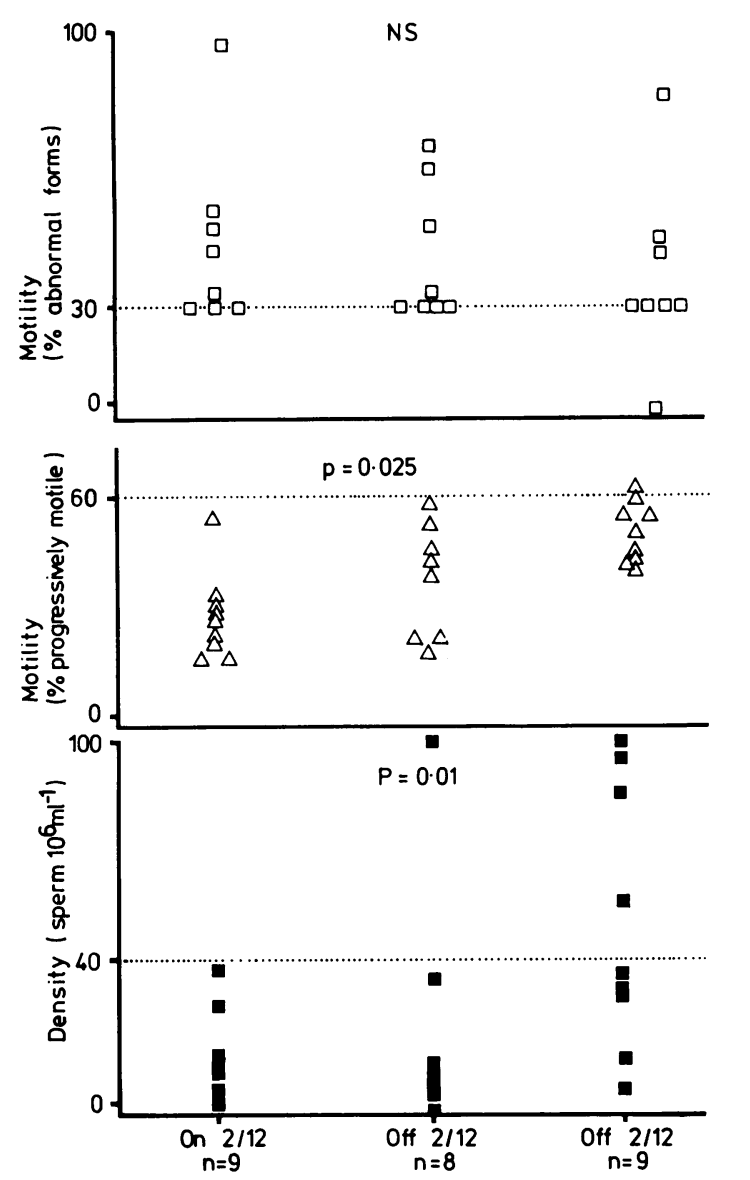

Fig. 4 Sperm density, motility, and morphology in matched pairs of patients on and off sulphasalazine (Wilcoxon's).

tosterone and, prolactin in the two groups of the various time intervals.

\section{Discussion}

Sulphasalazine has been used in the treatment of ulcerative colitis since $1942 .{ }^{9}$ Long-term maintenance therapy is now standard practice, as the
Table 2 Pregnancies after SASP withdrawal

\begin{tabular}{rccl}
\hline Patient & $\begin{array}{l}\text { Duration } \\
\text { SASP } \\
(y r)\end{array}$ & $\begin{array}{l}\text { Pregnant after } \\
\text { SASP stopped } \\
\text { (months) }\end{array}$ & Result \\
\hline 1 & 3 & 1 & FTND1 \\
2 & $2 \cdot 7$ & 2 & Awaited \\
12 & 5 & 6 & Awaited \\
4 & 6 & $3 / 52$ & $\begin{array}{l}\text { Spontaneous } \\
\text { abortion }\end{array}$ \\
4 & $2 / 12$ & 2 & FTND \\
4 & 1 & 2 & Awaited \\
5 & 10 & $3 \cdot 5$ & Awaited \\
6 & 5 & $2 \cdot 5$ & FTND \\
7 & 3 & $2 \cdot 5$ & FTND \\
8 & 4 & $2 \cdot 5$ & FTND \\
\hline
\end{tabular}

1FTND: delivery of a normal infant at full-term gestation.

drug is effective in preventing relapses. ${ }^{10}$ The drug is also being used increasingly in Crohn's disease, ${ }^{11}$ as a result of recent trials. It has been estimated by Pharmacia that approximately 25000 patients are taking sulphasalazine in the United Kingdom, a significant proportion of whom will be males in the productive age.

An important new side-effect from such a widely used and long-accepted drug is unexpected, but is understandable in this instance from the way in which the clinical care that the husband of an infertile couple receives is fractionated: he is seen by different departments for infertility and for inflammatory bowel disease. Levi et al. and Toth $^{4}$ independently and simultaneously reported preliminary studies associating male infertility and sulphasalazine treatment. The present study enlarges the initial experience and reports the time course of the effezt. The small group of patients with newly diagnosed inflammatory bowel disease had normal semen analyses. This implies, within the limitation of the small numbers, that neither this disorder nor the ill health accompanying it disturbs semen quality. This contrasts with the gross abnormalities found in all three semen qualities after more than two months of sulphasalazine therapy. Of the 18 patients on the drug for more than two months one had a density of $40 \times 10^{6} \mathrm{sperm} / \mathrm{ml}$, the lower limit of normal, and only one patient had a value above this. This made us begin to suspect

Table 1 Comparison of patients complaining of infertility and those not

\begin{tabular}{|c|c|c|c|c|}
\hline & Normal & $\begin{array}{l}\text { Complaining } \\
(\text { mean } \pm S E M)\end{array}$ & $\begin{array}{l}\text { Not complaining } \\
(m e a n \pm S E M)\end{array}$ & $\begin{array}{l}\text { Difference } \\
\text { (Mann-Whitney) }\end{array}$ \\
\hline $\begin{array}{l}\text { Density } \\
(\text { sperm } \times 106 / \mathrm{ml}) \\
\text { Motility }\end{array}$ & $\geqslant 40$ & $15 \cdot 1 \pm 3 \cdot 8$ & $25 \cdot 9 \pm 6 \cdot 9$ & NS \\
\hline (\% progressively motile) & $\geqslant 60$ & $22 \pm 4 \cdot 2$ & $35 \pm 6 \cdot 2$ & NS \\
\hline ( $\%$ abnormal forms) & $\leqslant \mathbf{3 0}$ & $49 \pm 8 \cdot 0$ & $38 \pm 4 \cdot 6$ & NS \\
\hline
\end{tabular}


Table 3 Acetylator phenotype and semen quality

\begin{tabular}{|c|c|c|c|c|c|}
\hline Phenotype & $N$ & $\begin{array}{l}\text { Density } \\
(\text { mean } \pm S E M) \\
\text { Sperm } \times 10^{6} / \mathrm{ml}\end{array}$ & $\begin{array}{l}\text { Motility } \\
\text { (mean } \pm S E M) \\
\% \text { progressively motile }\end{array}$ & $\begin{array}{l}\text { Morphology } \\
\text { (mean } \pm \text { SEM) } \\
\% \text { abnormal forms }\end{array}$ & Difference \\
\hline
\end{tabular}

NS: no significant difference in Mann-Whitney Test.

Table 4 Hormone studies

\begin{tabular}{|c|c|c|c|c|c|}
\hline Hormone & Normal range & $\underset{(\min )}{\operatorname{Time}}$ & $\begin{array}{l}\text { Patients on } S A S P \\
(\text { mean } \pm S E M)\end{array}$ & $\begin{array}{l}\text { Patients off } S A S P \\
(\text { mean } \pm S E M)\end{array}$ & $\begin{array}{l}\text { Difference } \\
\text { (Mann-Whitney) }\end{array}$ \\
\hline $\begin{array}{l}\text { LH }(u / l) \\
\text { LH }(u / l) \\
\text { LH (u/l) } \\
\text { LH (u/l) } \\
\text { FSH (u/l) } \\
\text { FSH (u/l) } \\
\text { FSH (u/l) } \\
\text { FSH (u/l) } \\
\text { Prolactin (mu/l) } \\
\text { Testosterone (nmol/l) } \\
\text { Testosterone (nmol/l) } \\
\text { 5-alphadihydro- } \\
\text { testosterone (nmol/l) }\end{array}$ & $\begin{array}{c}3-12 \\
0 \cdot 5-5 \\
100-620 \\
9.4-30 \cdot 2\end{array}$ & $\begin{array}{r}0 \\
20 \\
60 \\
120 \\
0 \\
20 \\
60 \\
120 \\
0 \\
0 \\
120 \\
-20 \\
\end{array}$ & $\begin{array}{c}5 \cdot 2 \pm 0 \cdot 8 \\
33 \cdot 0 \pm 4 \cdot 3 \\
30 \cdot 0 \pm 2 \cdot 6 \\
23 \cdot 0 \pm 4 \cdot 3 \\
4 \cdot 8 \pm 2 \cdot 7 \\
9 \cdot 0 \pm 3 \cdot 7 \\
8 \cdot 9 \pm 0 \cdot 9 \\
10 \cdot 5 \pm 5 \cdot 4 \\
134 \pm 23 \\
12 \cdot 3 \pm 1 \cdot 4 \\
12 \cdot 6 \pm 1 \cdot 6 \\
1 \cdot 3 \pm 1 \cdot 73\end{array}$ & $\begin{array}{l}4 \cdot 3 \pm 1 \cdot 3 \\
19 \pm 2 \cdot 9 \\
19 \cdot 5 \pm 1 \cdot 9 \\
14.9 \pm 1 \cdot 3 \\
1 \cdot 8 \pm 0.3 \\
4 \cdot 0 \pm 1 \cdot 2 \\
4 \cdot 6 \pm 0.9 \\
3 \cdot 9 \pm 0.9 \\
80 \pm 18 \\
8 \cdot 8 \pm 1 \cdot 9 \\
11.4 \pm 1 \cdot 4 \\
1.2 \pm 0.3\end{array}$ & $\begin{array}{l}\text { NS } \\
\text { NS } \\
\text { NS } \\
\text { NS } \\
\text { NS } \\
\text { NS } \\
\text { NS } \\
\text { NS } \\
\text { NS } \\
\text { NS } \\
\text { NS } \\
\text { NS }\end{array}$ \\
\hline
\end{tabular}

poor compliance in the latter. Not a single patient in this group had normal motility, and only six had normal morphology. The consistency with which sulphasalazine impoverishes semen quality is remarkable.

Of the eight patients complaining of infertility seven had fathered children before they started treatment with sulphasalazine, thereby proving their fertility. This group did not appear to be an especially susceptible subgroup, as their semen quality was not significantly different from those who had not spontaneously complained of infertility. Ten children were fathered by eight of these patients (group 3) after withdrawal of sulphasalazine. This demonstrates concordance between laboratory data and proven fertility. Improvement in measured semen quality is underlined by the significant changes evident in the match pair analysis on withdrawal of sulphasalazine. There is additional evidence of concordance between measured semen quality and fertility in that the mean interval between withdrawal of sulphasalazine and successful impregnation was 2.5 months, laboratory data improving after two months. The demonstrated two month recovery period indicates an effect relatively early in the process of spermatogenesis, which is believed to take $74 \pm 4$ days in a human. ${ }^{12}$

Consideration of the differences between the group who had never ingested sulphasalazine and those on the drug for longer or less than two months indicated the possible mode of action in that motility is impaired before density. In view of this recovery period and the probable effect early in spermatogenesis such a result would be expected. If sulphasalazine or one of its metabolites were generally and directly toxic to spermatogenesis such a time lapse would be required before poisoned developing gametes could make their absence evident in a falling sperm density. It seems likely that sulphasalazine is exerting a direct toxic effect on gametes in varying stages of development. The failure of morphology to improve on withdrawal of sulphasalazine is demonstrated both in the matched pair and group data comparisons. This is a source of potential worry, the question of the persisting or permanent effect of sulphasalazine and potential terogenicity arising. It is interesting that the pregnancy fathered after the drug had been withdrawn for approximately three weeks resulted in a spontaneous abortion. The data are insufficient to draw any firm conclusions in this regard, however, and additional study is indicated in this area. The question of persisting abnormality may be related to that of gonadal damage. A single normal human testicular biopsy taken before the semenspoiling effect of sulphasalazine was recognised was histologically quite normal. Acquisition of further such human material is now unethical. No histological evidence of a structural lesion had been demonstrated in rats after five weeks' 
treatment with sulphasalazine in a high dose (unpublished data), but more prolonged studies are under way. The metabolic fate of sulphasalazine is similar in humans and rats. ${ }^{13}$

The semen spoiling principal of sulphasalazine remains unidentified. Of orally ingested sulphasalazine approximately $33 \%$ is absorbed in the small intestine whence it undergoes an enterohepatic circulation. Acetylated and free sulphasalazine subsequently appear in the urine. Of the sulphasalazine which passes to the large bowel bacterial action is responsible for the azo reduction to 5 amino salicylic acid and sulphapyridine. ${ }^{13-19}$ Seventy-five per cent of the resulting 5 amino salicylic acid moiety is then recoverable unchanged in the faeces as against just over 7\% for the sulphapyridine moiety. The fate of $a b-$ sorbed sulphapyridine is then one of either acetylation or glucuronide conjugation or both in the liver. This generates acetyl-sulphapyridine, glucuronide-sulphapyridine, and acetyl-glucuronide-sulphapyridine. These metabolites are then excreted in the urine along with some free sulphapyridine. The exact proportions of these metabolites present depends in part upon the acetylator phenotype. ${ }^{17-18}$ Despite the inconclusive results of the acetylator phenotype study reported above and its inability to indict sulphapyridine or one of its metabolites as being responsible for semen spoiling, it would seem that it is the sulphonamide portion of sulphasalazine which is accountable. Reports have appeared in the literature linking co-trimoxazole (a sulphonamide containing mixture) and dapsone (a sulphonamide related molecule) to impaired semen quality. ${ }^{20}$ An earlier report in the French literature links sulphonamide treatment for acute gonorrhoea with abnormal semen density, sperm motility, and morphology. ${ }^{21}$ These reports and the poor absorption of 5 amino salicylic acid supports this hypothesis, although sulphasalazine itself may be responsible. It is also possible that different metabolites are responsible for different effects on semen quality. This might account for the apparent failure of the acetylator phenotype study to act as a discriminator. The small size of the study leaves the matter unresolved. Similarly, the numbers studied did not allow the effect of dosage of sulphasalazine to be assessed.

Similar limitations again, those of size, must apply to the results of the hormone studies reported. Though the leuteinising hormone, follicle stimulating hormone, and testosterone levels were all slightly higher in patients on the drug, they remained within the normal range and the differences were not statistically significant. These results suggest tentatively that the effect of sulphasalazine or its metabolites is outside the feedback loops of the hormone systems controlling spermatogenesis in the human. This is in favour of a directly toxic effect on spermatozoa in keeping with the finding that motility is impaired before density. This generates speculation about the possibility of non-hormonal male contraception.

These findings are important in that they emphasise a new and seemingly widespread effect of chronic medication in young males. Few other such clinical situations exist in which males of reproductive age and desire are required to comply with chronic medication. It may be that further studies of males ingesting related compounds are indicated-for example, sulphonamide-related diuretics.

\section{Conclusion}

Chronic ingestion of sulphasalazine in the human is associated with abnormal semen quality. This can be expected to be a widespread finding and not an idiosyncratic response to the drug. Semen quality improves on drug withdrawal and fertility may then be demonstrated. The exact mechanism of semen impairment remains unexplained. The absence of a major hormone disturbance and the time course of events support the hypothesis that oligospermia may be due to a direct toxic effect on immature and developing spermatozoa. Sulphapyridine could be the toxic mediator.

We would like to thank Pharmacia for supporting Dr S. Toovey and Professor N Jeffcoate for hormone studies.

\section{References}

${ }^{1}$ Levi AJ, Fisher AM, Hughes L, Hendry WF. Male infertility due to sulphasalazine. Lancet 1979; 2: 276-8.

${ }^{2}$ Grieve J. Male infertility due to sulphasalazine. (Letter) Lancet 1979; 2:464.

${ }^{3}$ Traub AI, Thompson W, Carville J. Male infertility due to sulphasalazine. (Letter) Lancet 1979; 2: 639-40.

4Toth A. Reversible toxic effect of salicylazosulphapyridine on semen quality. Fertil Steril 1979; 31(5): 538-40.

5 Jarnerot G. Manlig Intertilitet Orsakad av Salazosulfapyridin (Swe). Läkartidningen 1980; 77:1444.

"Schröder H. Simplified method for determining the acetylator phenotype. Brit Med J 1972; 3:506-7.

'Collins WP, Mansfield MD, Allandina NS, Somerville IF. Radioimmunoassay of plasma testosterone. J Steroid Biochem 1972; 3:333-48. 
${ }^{8}$ Mansfield MD, Johnson MN. The determination of testosterone and five related steroids in human plasma. Proceedings of the Fourth International Congress on Human Steroids, Mexico City. J Steroid Biochem 1973; 5:305.

${ }^{9}$ Svartz N. Salazopyrin, a new sulfanilamide preparation. Acta Med Scand 1942; 110:577-98.

${ }^{10}$ Misiewicz JJ, Lennard-Jones JE, Connell AM, Baron JH, Jones FA. Controlled trial of sulphasalazine in maintenance therapy for ulcerative colitis. Lancet $1965 ; 1: 185-8$.

${ }^{11}$ The National Co-operative Crohn's disease study. Gastroenterology 1979; 77:825-944.

${ }^{12}$ Heller CG, Clermant Y. Kinetics of the germinal epithelium in man. Recent Prog Horm Res 1964; 20:545.

${ }^{13}$ Schröder H, Gustafsson BE. Azo-reduction of salicylazosulfapyridine by germ free and conventional rat. Xenobiotica $1973 ; 3: 225-31$.

14Van Hees DAM, Tuinte JHM, Van Rossum JM, Van Tangeren JHM. Influence of intestinal transit time of azo reduction of salicyazosulphapyridine (Salazopyrin). Gut 1979; 20:300-4.

${ }^{15}$ Das KM, Eastwood MA, McManus JPA, Sircus W. The metabolism of salicylazosulphapyridine in ulcerative colitis. I The response to treatment in patients. Gut 1973; 14:631-6.

${ }^{16}$ Das KM, Eastwood MA, McManus JPA, Sircus W. The metabolism of salicylazosulphapyridine in ulcerative colitis. II The relationship between metabolites and the progress of disease studied in out-patients. Gut 1973; 14:637-41.

${ }^{17}$ Schröder H, Lewkonia M, Price-Evans DA. Metabolism of salicylazosulphapyridine in healthy subjects and in-patients with ulcerative colitis. Clin Pharmacol Ther 1973; 14(5):802-9.

${ }^{18}$ Schröder H, Price-Evans DA. The polymorphic acetylation of sulphapyridine in man. $\mathrm{J}$ Med Genet 1971; 9:168-71.

19Pepperform MA, Goldman P. The role of intestinal bacteria in metabolism of salicylazosulfapyridine. J Pharmocol Exp Ther 1972; 181:555-62.

${ }^{20}$ Murdia A, Mathur V, Kothari LK, Singh KP. Sulpha-Trimethoprim combinations and male infertility. (Letter) Lancet 1978; 2:375-6.

21 Jaubert A, Motz C. Action inhibitrice de certains derives sulfo-conjugues des amines aromatiques sur la spermatogenese de l'homme (Fre). Presse Med 1938; 46:237. 